\title{
Male mate choice in a sexually cannibalistic species: male escapes from hungry females in the praying mantid Tenodera angustipennis
}

\author{
Mika Kadoi $^{1} \cdot$ Kotaro Morimoto $^{2} \cdot$ Yasuoki Takami $^{2}$ (I)
}

Received: 21 October 2016/Accepted: 11 January 2017/Published online: 27 January 2017

(C) Japan Ethological Society and Springer Japan 2017

\begin{abstract}
While competing males and choosy females may be common in animal mating systems, male choice can evolve under certain conditions. Sexual cannibalism is such a condition because of the high mortality risk for males. In mantids, female body condition is associated with male mate preference, with fat females preferred, due to at least two reasons: females in poor nutritional condition are likely to attack and predate males, and fat females can potentially increase the number of offspring. Thus, the risk of cannibalism and female fecundity can influence male mating behavior. In this study, we attempted to separate these factors by using the praying mantid Tenodera angustipennis to examine whether male preference for fat female mantids was based on avoiding sexual cannibalism (cannibalism avoidance hypothesis) or preference for female fecundity (fecundity preference hypothesis). The feeding regimes were experimentally manipulated to discriminate between the effects of female fecundity and female hunger status on male and female mating behaviors. We found that recently starved females more frequently locomoted toward the male, and that male abdominal bending was less intensive and escape was sooner from recently starved females. These female and male behavioral responses to female hunger condition may reveal male avoidance of dangerous females in this mantid.
\end{abstract}

Yasuoki Takami

takami@ people.kobe-u.ac.jp

1 Faculty of Human Development, Kobe University, Tsurukabuto 3-11, Nada, Kobe 657-8501, Japan

2 Graduate School of Human Development and Environment, Kobe University, Tsurukabuto 3-11, Nada, Kobe 657-8501, Japan
Keywords Mate preference - Mating behavior - Sexual cannibalism $\cdot$ Sexual conflict $\cdot$ Sexual selection

\section{Introduction}

Competing males and choosy females are typical sex roles in animal mating (Andersson 1994), with the likely ultimate cause being anisogametic reproduction: males produce many tiny sperm, but females produce few large eggs. However, choosy males, i.e., male mate choice, have evolved in various groups of animals (Bonduriansky 2001). Theory predicts that male mate choice can evolve when the availability of female mates is greater than the mating capacity of males, when female quality is variable, and/or when the benefit of mate choice is greater than the cost (Bonduriansky 2001; Edward and Chapman 2011). Species that engage in sexual cannibalism are likely to satisfy these conditions (Elgar and Schneider 2004): the opportunity for male multiple mating is limited because of the risk of sexual cannibalism (Andrade 1996, 1998), the variation in nutritional condition and therefore hunger status among predatory females may be large (Barry 2013), and avoidance of sexual cannibalism can be beneficial for males because of future mating opportunities (Moya-Laraño et al. 2004; Fromhage and Schneider 2005; Gemeno and Claramunt 2006; Lelito and Brown 2006; Barry et al. 2009; Scardamaglia et al. 2015). Thus, sexually cannibalistic species provide a good opportunity to study the evolution of male mate choice.

Sexual cannibalism is a strong cause of sexual conflict (Elgar 1992; Elgar and Schneider 2004; Schneider 2014), and the fitness cost to predated males is large with the loss of future mating opportunities (Elgar 1992; Johns and Maxwell 1997; Elgar and Schneider 2004). By contrast, 
sexual cannibalism is likely adaptive for females because of the nutritional benefits (Birkhead et al. 1988; Barry et al. 2008; Welke and Schneider 2012; cf. Arnqvist and Henriksson 1997; Maxwell 2000), and may be a mechanism to control the duration of copulation and transfer of sperm (Andrade 1996; Elgar et al. 2000). Theory predicts that selection favors counteradaptations to avoid the costs of sexual conflict (Arnqvist and Rowe 2005). Therefore, male mating behavior is hypothesized to evolve as a counteradaptation to avoid the cost of sexual cannibalism, which is a hypothesis generally supported by studies of sexually cannibalistic spiders (Moya-Laraño et al. 2004; Fromhage and Schneider 2005) and mantids (Gemeno and Claramunt 2006; Lelito and Brown 2006; Prokop and Václav 2008; Barry et al. 2009; Scardamaglia et al. 2015). Male mate choice is one facet of male mating behavior, and may constitute a counteradaptation to avoid sexual cannibalism; For example, males of the mantid Parastagmatoptera tessellata preferred low-risk females that did not show attacking behavior compared with high-risk females that attacked another male (Scardamaglia et al. 2015). Postmating mate choice (e.g., strategic ejaculate allocation by males, and biased sperm uptake and usage by females) may also be possible, but only a little is known in mantids (Holwell et al. 2010; Jayaweera and Barry 2015).

Female body condition (relative body mass over a fixed body size) is frequently associated with male mate preference in mantids, with a preference for fat females (Barry 2010; Barry et al. 2010; Maxwell et al. 2010a, b). A proximal cause for this male preference is that more fecund females are more likely to emit pheromones, thereby attracting males (Lelito and Brown 2008; Barry et al. 2010; cf. Barry 2015). For possible ultimate causes, two hypotheses are proposed to explain male preference for fat females in mantids. As previously mentioned, according to the cannibalism avoidance hypothesis, males lower the risk of sexual cannibalism by preferring fat females, because these females are relatively satiated and unlikely to attack males (Birkhead et al. 1988; Barry et al. 2009; Maxwell et al. 2010b). Alternatively, according to the fecundity preference hypothesis, male preference is explained by the higher fecundity of fat females. Although these two hypotheses are not mutually exclusive, the distinction between the two is important to explain the evolution of male mate choice. The cannibalism avoidance hypothesis is supported in many studies of sexually cannibalistic species (Moya-Laraño et al. 2004; Fromhage and Schneider 2005; Gemeno and Claramunt 2006; Lelito and Brown 2006; Prokop and Václav 2008; Barry et al. 2009, 2010; Maxwell et al. 2010b; Scardamaglia et al. 2015), suggesting that risk avoidance is relevant in the evolution of male mate choice. By contrast, according to the fecundity preference hypothesis, male preference for fecund females plays a role in the evolution of male mate choice in sexually cannibalistic species. Because male preference for fecund females is found generally in a variety of animals (Andersson 1994), the preference for fecund females is likely ancestral in sexually cannibalistic species. To determine whether cannibalism avoidance or fecundity preference explains the evolution of male choice, the effects of sexual cannibalism risk and female fecundity must be separated experimentally. However, in previous studies, only the risk of sexual cannibalism was examined (Moya-Laraño et al. 2004; Fromhage and Schneider 2005; Gemeno and Claramunt 2006; Lelito and Brown 2006; Prokop and Václav 2008; Scardamaglia et al. 2015) or the two effects were examined without discrimination (Barry et al. 2009, 2010; Maxwell et al. 2010b).

In this study, the two hypotheses proposed for the evolution of male mate choice (i.e., cannibalism avoidance and fecundity preference) were examined with the praying mantid Tenodera angustipennis. Both the adult and nymph of this species engage in cannibalism, as revealed by an enclosure study (Inoue and Matsura 1983), but the rate of sexual cannibalism in the wild is still unclear. Precopulatory sexual cannibalism is usually observed in experimental mating, and cannibalized males are often able to mate with the predator female (Y. Takami, unpublished data). We manipulated female fecundity and hunger status independently via altered feeding regimes and examined mating behaviors of males and females within an experimental arena. Our experiment was designed to examine sequential male mate choice (i.e., one male encounters one female at a time), because mantid mates are expected to be often encountered sequentially (Barry and Kokko 2010). The cannibalism avoidance hypothesis predicts that males will avoid recently starved (hungry) females. The fecundity preference hypothesis predicts that males will prefer more fecund females. Male preference for, and avoidance of, a certain female was evaluated by examining male mating behaviors. The purpose of this study is to discriminate between the effects of sexual cannibalism risk and female fecundity on male mate preference in a sexually cannibalistic species.

\section{Materials and methods}

\section{Organism}

One hundred twenty juveniles of T. angustipennis were collected from several grasslands around rice fields in Kobe, Japan, from the end of July to the end of August 2013. The mantids were housed individually in tall plastic cases $(13 \mathrm{~cm}$ diameter $\times 20 \mathrm{~cm}$ high) topped with cotton mesh to facilitate molting, fed one cricket (Gryllus 
bimaculatus; $0.447 \pm 0.107 \mathrm{~g}, N=17$ ) three times per week, and provided with tissue paper soaked with water. Cases were placed in incubators maintained at $25{ }^{\circ} \mathrm{C}$ with a 16 L:8 D photoperiod. Emerged adults were housed individually in $860-\mathrm{ml}$ columnar plastic cases $(13 \mathrm{~cm}$ diameter $\times 10 \mathrm{~cm}$ high) placed in an incubator with a $12 \mathrm{~L}: 12 \mathrm{D}$ photoperiod. Adult males were fed one cricket twice per week. Fifty-five mantids were excluded from the following experiments because of early death or parasitism of horsehair worms or tachinid flies.

\section{Manipulation of female fecundity and the risk of sexual cannibalism}

Independent control of female fecundity and the risk of sexual cannibalism (female hunger status) were achieved by manipulating female feeding regimes at different times before mating. To control female fecundity, approximately half of newly emerged adult females were fed three times per week (high-fecundity females, $N=18$ ), with the other half fed once per week (low-fecundity females, $N=16$ ). These feeding schedules (hereafter, the fecundity treatments) were continued for $50 \pm 6.1$ days before the experiment (=the age of experimental females from eclosion). The age of experimental males from eclosion was $50 \pm 6.4$ days. The weight of cricket used here was the same as above. Within this period, the expectation was that the growth of the ovaries would increase with the increase in the consumption of food (i.e., high-fecundity females). To control female hunger (hereafter, the hunger treatments), half of the females from each fecundity treatment were fed one cricket immediately before the mating experiment within their housing cases (recently fed females, $N=9$ and 8), with the other half not fed (recently starved females, $N=9$ and 8). Thus, the treatment combinations of fecundity and hunger resulted in four groups of females: (1) high fecundity and recently fed (HF, $N=9$ ), (2) high fecundity and recently starved (HS, $N=9$ ), (3) low fecundity and recently fed (LF, $N=8$ ), and (4) low fecundity and recently starved (LS, $N=8)$. The period of starvation for recently starved females was 2 or 3 days. Although 34 females were used in the experiment, one male was mistakenly paired with four LF females. Thus, we retained the first record of this male and discarded the three following cases in the analyses of results of the mating experiments (i.e., $9 \mathrm{HF}, 9 \mathrm{HS}, 5 \mathrm{LF}$, and $8 \mathrm{LS}$ ).

To validate the treatments of the experimental feeding regimes, the fixed body size and body condition of the males and females and the ovary mass were compared among the four treatment groups. As a fixed indicator of body size, the length of the pronotum was measured using digital calipers to the nearest $0.01 \mathrm{~mm}$. Body mass was weighed using an electronic balance to the nearest $0.01 \mathrm{~g}$ immediately before the mating experiment. As an indicator of body condition, the ratio of body mass/pronotum length was calculated (Barry et al. 2008, 2010). Additionally, the residual body masses from linear regressions of fixed body sizes were also used as an indicator of body condition.

After the mating experiment, females were dissected to remove the pair of ovaries, which were weighed using the electronic balance to the nearest $0.1 \mathrm{mg}$. Fixed body sizes, body condition, and ovary mass were analyzed using generalized linear models (GLMs) with identity link and normal distribution, with the fecundity treatment, the hunger treatment, and their interaction as independent variables.

\section{Mating experiment}

To examine the effects of female fecundity and hunger status on the mating behaviors of males and females, the behavior of paired mantises was observed in an experimental arena. Thus, our experiment was designed to examine an aspect of sequential mate choice (Barry and Kokko 2010). The arena was an opaque plastic box $(60 \mathrm{~cm}$ length $\times 38 \mathrm{~cm}$ width $\times 27 \mathrm{~cm}$ height) with $5-\mathrm{mm}$ grid paper on the bottom (Fig. 1), the walls of which was

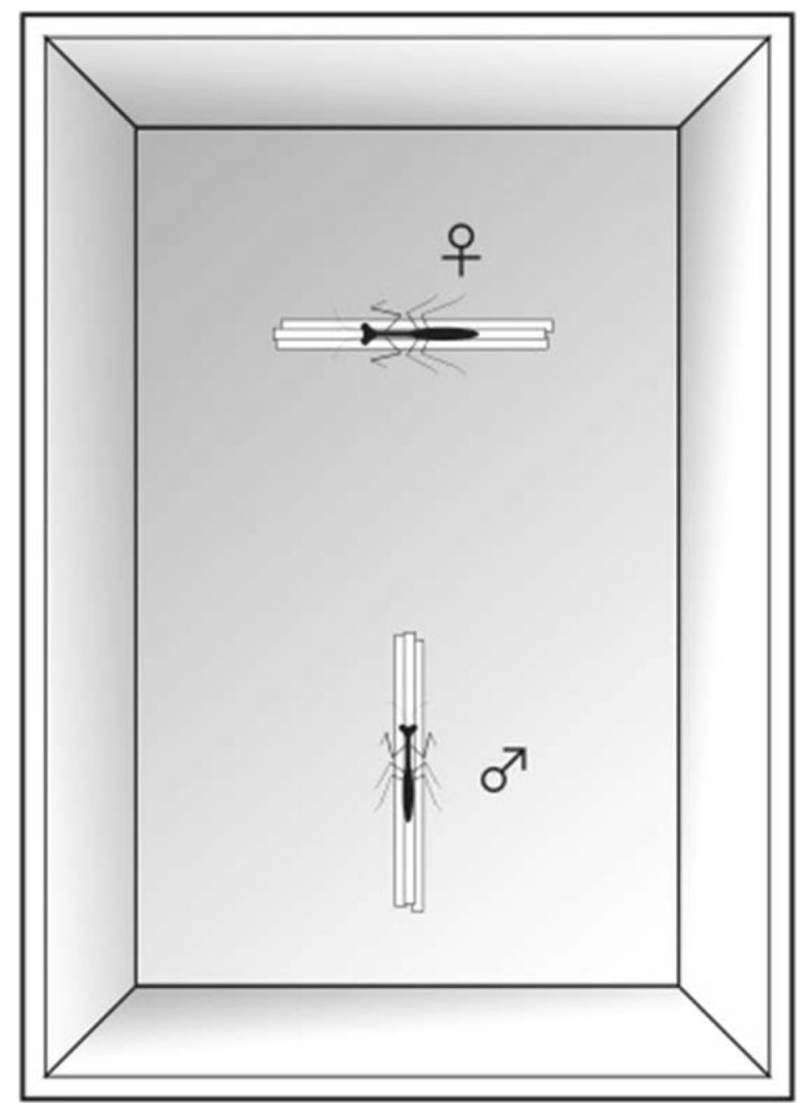

Fig. 1 Apparatus used in the mating experiments 
opaque to avoid visual disturbances from outside the arena. However, mantises walked on the bottom and walls of the arena, and when mantises stood on the walls, primarily immediately before escape, avoiding visual disturbances was likely not effective. A male and a female were arbitrarily chosen, and each was perched on a bunch of wood sticks (20 cm long and $4 \mathrm{~mm}$ diameter) separated by $30 \mathrm{~cm}$ at the bottom of the arena. This distance between the male and female was similar to related studies (at most $45 \mathrm{~cm}$ in Gemeno and Claramunt 2006; $20 \mathrm{~cm}$ in Barry et al. 2009). The male was positioned to face the female, whereas the female was positioned perpendicularly to the male (Fig. 1). The direction of the female head (to the left or to the right; Fig. 1) was arbitrary, but the female was positioned for males to visually perceive female body condition, presumably via female abdominal thickness (Maxwell et al. 2010b). After the mantids settled, a paper wall that separated the pair was removed, and the behaviors were recorded using a digital video camera (Sanyo Xacti CA100) placed $120 \mathrm{~cm}$ above the arena. Observations were terminated when copulation or sexual cannibalism occurred, or when either the male or female escaped from the arena. Total experimental time was recorded to the nearest $1 \mathrm{~s}$.

Three female and five male behaviors were extracted from the video recordings. The following female behaviors were extracted: (1) direction of first locomotion (moving at least $1 \mathrm{~cm}$, toward the male or not), (2) whether the female attempted to attack the male by jerking her raptorial forelegs, and (3) whether sexual cannibalism occurred. These female behaviors were measured as indicators of female aggressiveness. The following male behaviors were extracted: (1) latency to first abdominal bending, (2) number of abdominal bendings, (3) latency to mounting, (4) whether copulation occurred, and (5) latency to escape. Abdominal bending behavior is a part of male mating behavior occurring in response to encounters with females, which could indicate a part of male courtship (Liske and Davis 1987). If this is the case, it is assumed that shorter latency to abdominal bending and larger number of bendings can be interpreted as positive male preference. However, abdominal bending can also be a part of male cautious approach (Lelito and Brown 2006; Brown et al. 2012), and if this is the case, the above assumption cannot be met. Thus, we measured this male behavior as an indicator of male responses to female fecundity and hunger status irrespective of the direction of responses. Shorter latency to mount and higher frequency of copulation are assumed to be positive male preference, while shorter latency to escape is assumed to be mate avoidance. Escape was judged when the focal animal walked or flew out from the mating arena. The direction of first locomotion was determined with respect to whether or not the distance between the male and female decreased (i.e., whether they approached each other or not). Latencies were measured to the nearest $1 \mathrm{~s}$.

\section{Hypothesis testing}

To determine the effects of fecundity and hunger treatments on the variation in female and male behaviors, statistical models were constructed with each behavioral trait as a dependent variable and the fecundity and hunger treatments in females and their interaction as independent variables. GLMs with logit link and a binominal distribution were constructed for binary data, and with log link and a Poisson distribution for count data. Models based on parametric survival analysis were used for latency data, in which Weibull, log-normal, Fréchet, exponential, and loglogistic distributions were used to verify model suitability, with the most appropriate distribution chosen by consulting the Akaike information criterion corrected for small sample sizes (AICc). When no event occurred after the observation period, the event was treated as a censored case and the total experimental time was used for latency. Note that the analysis of latencies to a certain event was not affected by termination by other events, because cases that end with other events provide only information that a focal event had not occurred at the time of occurrence of other events. Since we tested hypotheses repeatedly by focusing on multiple behaviors, statistical significance was controlled by adjusting the false discovery rate (Benjamini and Hochberg 1995). Statistical analyses were performed using JMP version 8 (SAS Institute 2009), in which overdispersion in GLM analyses was corrected by implementing the function in the software.

\section{Results}

\section{Female fecundity and hunger status}

As expected, the experimental feeding treatments influenced female fecundity and hunger (Table 1). Fixed body size did not differ among the four groups of females. Ovary mass was significantly higher in the high-fecundity groups, and differed between HF and HS females and LF and LS females, indicating that fecundity was manipulated as expected and effects were independent of hunger treatment. Female body condition (body mass over a fixed body size) was significantly higher in both the high-fecundity and the recently fed groups, and differed between all pairs of feeding types. Therefore, feeding immediately before the experiment led to a further increase in female body condition that was independent of fecundity. Additionally, fixed body size and body condition in paired males were 


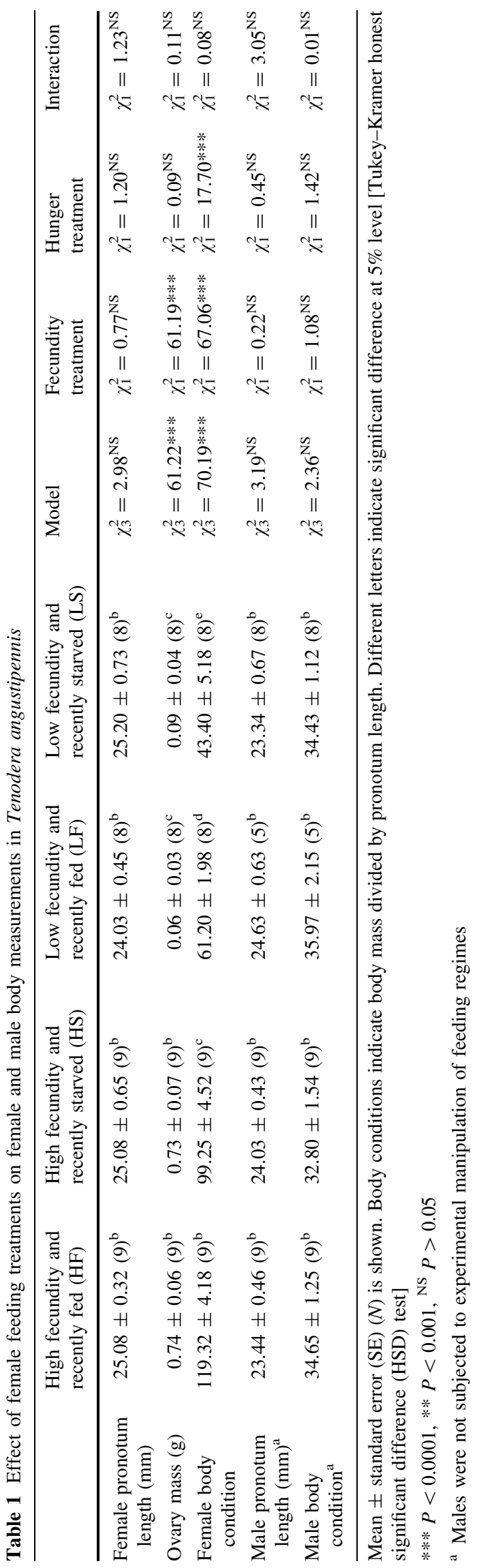

independent of female feeding treatments. The conclusions were identical when residual body mass was used as the indicator of body condition (results not shown).

\section{Mating experiment}

The duration of the mating experiment varied from 5.4 to $196.7 \mathrm{~min} \quad$ [mean \pm standard deviation $(\mathrm{SD})=42.7 \pm 40.8 \mathrm{~min}]$, and was significantly shorter for recently starved females [estimated times at termination of $50 \%(25,75 \%)$ of the experiment: HF 49.0 (27.0, 88.9) min; HS, 23.8 (13.1, 43.2) min; LF, 32.1 (17.7, 58.3) min; LS, $15.6(8.6,28.3) \mathrm{min}$; parametric survival model with log-normal distribution, $\chi_{2}^{2}=6.75, \quad P=0.034$, fecundity treatment, $\chi_{1}^{2}=1.66, P=0.198$, hunger treatment, $\left.\chi_{1}^{2}=4.69, P=0.030\right]$. Nine male escapes, thirteen female escapes, seven copulations, and two cases of sexual cannibalism resulted in termination of the experiments. Male escapes tended to result in shorter experimental period [estimated times at termination of $50 \%(25,75 \%)$ of the experiment: male escape, $13.6(7.8,23.6) \mathrm{min}$; female escape, 40.3 (23.2, 70.2) min; copulation, 38.6 (22.2, 67.1) min; sexual cannibalism, 22.6 (13.0, 39.3) min; parametric survival model with log-logistic distribution, $\chi_{3}^{2}=7.79$, $P=0.051]$. Among the statistical models used to explain male and female behaviors, the interaction terms were all nonsignificant $(P>0.05)$. Therefore, we removed the interaction terms from all final models (Table 2).

The direction of female's first locomotion was explained by female hunger treatment (Table 2). For recently starved females, movement toward the male was significantly more frequent [0\% (0/9) in $\mathrm{HF}, 11 \%(1 / 9)$ in HS, $0 \%(0 / 5)$ in LF, and 38\% (3/8) in LS] (Table 2). Female attack and sexual cannibalism were not subjected to statistical analyses because of small numbers of occurrences ( $N=4$ and 2 , respectively). Of the four attacks by females, one was by an HS female, one by an LF female, and the remaining two by LS females. The two cases of sexual cannibalism were by LS females.

Of the five male behavioral traits, three traits were significantly affected by female fecundity and/or hunger treatments (Table 2). Males began abdominal bending with low-fecundity females sooner than with high-fecundity ones (Fig. 2a), but this effect became nonsignificant after controlling for false discovery rate $(P>0.05)$. Males performed a significantly larger number of abdominal bending movements to recently fed females than to recently starved females (Fig. 2b). Males escaped significantly sooner when paired with recently starved females (Fig. 2c). Latency to mounting and copulation were not affected by the treatments, most likely because the experiment was more likely to be terminated by the escape of the male or female. 
Table 2 Effects of female fecundity and hunger (recent feeding status) on mating behavior in Tenodera angustipennis

\begin{tabular}{|c|c|c|c|c|c|c|c|c|c|c|}
\hline & \multicolumn{4}{|l|}{ Model } & \multicolumn{3}{|c|}{ Fecundity (high/low) } & \multicolumn{3}{|c|}{$\begin{array}{l}\text { Hunger (recently fed/recently } \\
\text { starved) }\end{array}$} \\
\hline & Type & Distribution & $\chi_{2}^{2}$ & $P$ & Estimate & $\chi_{1}^{2}$ & $P$ & Estimate & $\chi_{1}^{2}$ & $P$ \\
\hline \multicolumn{11}{|l|}{ Female behavior } \\
\hline $\begin{array}{l}\text { Direction of locomotion (male/ } \\
\text { other) }\end{array}$ & GLM & Binomial & 5.84 & 0.054 & $-0.629 \pm 0.549$ & 2.71 & 0.100 & $-1.083 \pm 0.772$ & 4.34 & $\mathbf{0 . 0 3 7}$ \\
\hline \multicolumn{11}{|l|}{ Male behavior } \\
\hline $\begin{array}{l}\text { Latency to first abdominal } \\
\text { bending }\end{array}$ & Survival & Fréchet & 6.01 & 0.050 & $0.826 \pm 0.329$ & 5.61 & 0.018 & $-0.512 \pm 0.327$ & 2.38 & 0.123 \\
\hline Number of abdominal bending & GLM & Poisson & 7.64 & 0.022 & $0.179 \pm 0.255$ & 0.52 & 0.473 & $0.648 \pm 0.274$ & 6.61 & $0.010 *$ \\
\hline Latency to mounting & Survival & Fréchet & 3.04 & 0.219 & $0.297 \pm 0.350$ & 0.70 & 0.403 & $0.590 \pm 0.349$ & 2.35 & 0.125 \\
\hline Copulation (yes/no) & GLM & Binomial & 0.02 & 0.990 & $-0.018 \pm 0.437$ & 0.00 & 0.968 & $-0.058 \pm 0.436$ & 0.02 & 0.894 \\
\hline Latency to escape & Survival & Fréchet & 8.25 & 0.016 & $0.073 \pm 0.311$ & 0.05 & 0.816 & $0.996 \pm 0.333$ & 7.64 & 0.006* \\
\hline
\end{tabular}

Significant effects $(P<0.05)$ in each model are shown in boldface, and indicated with asterisks after correction of the false discovery rate within the male

\section{Discussion}

The manipulation of feeding regimes influenced female body condition as expected. Ovary mass increased after fecundity treatment, and hunger treatment resulted in further increases in the differences in female body mass and body condition. Importantly, these effects of the fecundity and hunger treatments were independent of one another. As a result, the body condition of females varied gradually from HF to LS treatments (Table 1), with different proportions of eggs in the ovary and food in the gut as components of body condition, thereby variation in body condition may mainly reflect variation in abdominal thickness. Thus, high-food diet led to high body condition, high abdominal thickness, and many eggs. Although not measured in this study, the fecundity per se of females is also reflected in the degree of pheromone emissions (Lelito and Brown 2008; Barry 2010), which therefore can be another indicator of female fecundity to the male.

We found support for the suggestion that hungry females were more risky for the male. Recently starved females tended to approach the male (Table 2), suggesting that one of the tactics used by males to avoid sexual cannibalism, i.e., careful approaches to risky females (Gemeno and Claramunt 2006; Lelito and Brown 2006; Barry et al. 2008, 2010; Maxwell et al. 2010b; Scardamaglia et al. 2015), could be compromised by this female behavior. Since mantids are ambush predators and switch to be active when the object (mostly prey) is detected (Inoue and Matsura 1983), the direction of female's first locomotion can be the response to the experimental male. However, we could not detect any effects of female fecundity and hunger conditions on the frequencies of female attack and sexual cannibalism, probably due to small sample sizes, although female attacks and resulting sexual cannibalism were all performed by females with relatively low body condition (i.e., HS, LF, and LS females). Females in low nutritional condition are likely to attack males in other mantid species (Birkhead et al. 1988; Barry et al. 2009; Maxwell et al. 2010b), while it is unclear whether these results from less fecund and/or hungry females. Female aggressiveness and the resultant rate of sexual cannibalism vary among mantid species (Maxwell 1999), possibly explaining the low frequencies of female attack and sexual cannibalism observed in this study. Further studies are necessary to determine whether female mating behaviors can be influenced by fecundity and/or hunger status, and to estimate the frequency of sexual cannibalism in the wild population of this species.

Female hunger status influenced male behavior, suggesting factors that influence male mate preference. Males showed abdominal bending behavior to recently fed females more intensely than to recently starved females, and males escaped sooner from recently starved females than from recently fed females (Table 2; Fig. 2b, c). Although it may be difficult to assume that male abdominal bending movement functions as a courtship to females and is interpreted as an indicator of male preference in mantids (Liske and Davis 1987), these results indicate that males responded to female hunger status but not to fecundity. Additionally, quick male escape from recently starved females may reflect mate rejection, suggesting another aspect of male mate preference as a male tactic to avoid sexual cannibalism. The smaller number of male abdominal bendings to recently starved females can be a by-product of the shorter latency to male escape. Mantid males are suggested to be likely not to reject a female when paired with a single female at one time (Barry and Kokko 2010), but this may depend on population density and sex ratio, which may vary among populations 

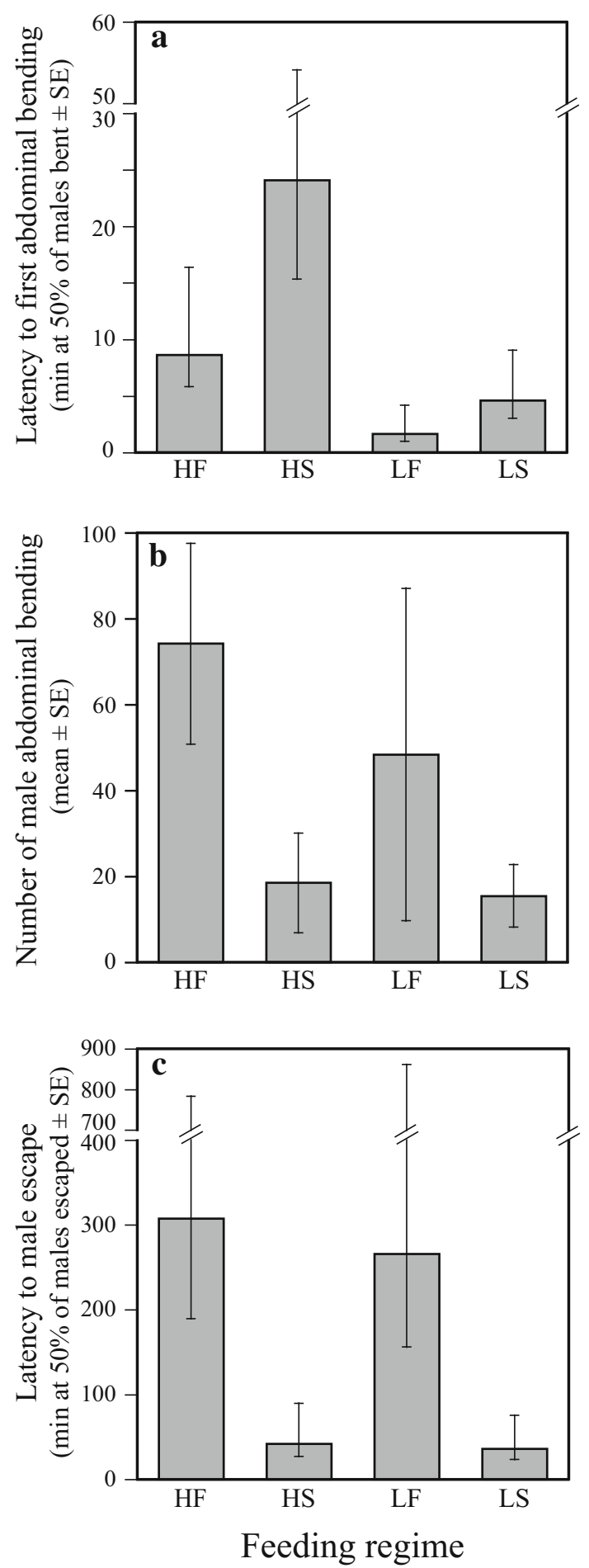

Fig. 2 Effects of fecundity and hunger treatments of females on male behavioral traits: a latency to male first abdominal bending, $\mathbf{b}$ number of male abdominal bending behaviors, and $\mathbf{c}$ latency to male escape from the mating arena. $H F$ high fecundity and recently fed, $H S$ high fecundity and recently starved, $L F$ low fecundity and recently fed, $L S$ low fecundity and recently starved

and species. The population density of T. angustipennis in the wild is about $5-9$ individuals $/ 100 \mathrm{~m}^{2}$, and there are up to 18 individuals $/ \mathrm{m}^{2}$ in a field with abundant prey in a reproductive season (Inoue and Matsura 1983; Matsura and Inoue 1999). Sex ratio is slightly female biased (proportion of male 0.2-0.4), and males decrease during the reproductive season (Matsura and Inoue 1999). Relatively high population density allows males to encounter multiple females, and female-biased sex ratio suggests that availability of female mates is greater than the mating capacity of males, providing support for a condition where male mate choice is likely to evolve (Bonduriansky 2001; Edward and Chapman 2011). Collectively, these female and male behavioral responses are consistent with the cannibalism avoidance hypothesis of male mate preference in mantids. By contrast, no evidence for the fecundity preference hypothesis was observed.

The direct cues for these male behaviors were difficult to determine based on the results; however, some possible cues were identified. The male response to female hunger status could be based on external features such as abdominal thickness; however, the difference in female body condition varied gradually between HF and LS females, and the body conditions of recently starved females (HS and LS) could not be discriminated from those of LF females based only on abdominal thickness (Table 1). Thus, the male response to female hunger status may involve detection of other cues. Female pheromone is a possible cue to male responses (e.g., Lelito and Brown 2008; Barry 2010, 2015; Maxwell et al. 2010a), but it remains to be determined whether female physiological condition can change instantaneously to emit pheromones following hunger treatment immediately before the experiment. Female behavior, i.e., approach to the male, may play a role as a cue to male behaviors. Males are likely discriminating among females based on a combination of long-range chemical signals or cues (pheromones) and then short-range chemical (pheromones) and visual (abdominal thickness and possibly female approach behavior) that reflects female hunger status.

In this study, caution should be exercised in interpreting the results because the experiments were performed with relatively small sample sizes. Although female attack and cannibalism, and mounting and copulation are important indicators of the risk of sexual cannibalism and male preference, respectively, we detected only a few cases of these behaviors and no significant effects of the treatments, probably because the experimental design allowed escapes. Relationships between the number of male abdominal bendings and latency to male escape are still unclear: the former behavior could result in the latter, and vice versa. Distinction of these causal relationships is important in understanding the behavioral process of mantid mating. Additionally, we need to know more about natural variations in female fecundity and hunger conditions and male opportunities to choose females in the field. Further studies 
using different experimental and natural settings are warranted to explore the evolutionary significance of male behavioral responses to female nutritional condition.

Acknowledgements We thank W. Maruyama, T. Shinohara, S. Takahashi, and T. Xia for their help in collecting mantids. We declare that we have no competing interests.

\section{Compliance with ethical standards}

Conflict of interest The authors declare that they have no conflict of interest.

Ethical approval This article does not contain any studies with human participants performed by any of the authors. All applicable international, national, and/or institutional guidelines for the care and use of animals were followed.

Informed consent Irrelevant.

\section{References}

Andersson M (1994) Sexual selection. Princeton University Press, Princeton

Andrade MCB (1996) Sexual selection for male sacrifice in the Australian redback spider. Science 271:70-72

Andrade MCB (1998) Female hunger can explain variation in cannibalistic behavior despite male sacrifice in redback spiders. Behav Ecol 9:33-42

Arnqvist G, Henriksson S (1997) Sexual cannibalism in the fishing spider and a model of the evolution of sexual cannibalism based on genetic constraint. Evol Ecol 11:255-273

Arnqvist G, Rowe L (2005) Sexual conflict. Princeton University Press, Princeton

Barry KL (2010) Influence of female nutritional status on mating dynamics in a sexually cannibalistic praying mantid. Anim Behav 80:405-411

Barry KL (2013) You are what you eat: food limitation affects reproductive fitness in a sexually cannibalistic praying mantid. PLoS One 8(10):e78164

Barry KL (2015) Sexual deception in a cannibalistic mating system? Testing the Femme Fatale hypothesis. Proc R Soc B 282:20141428

Barry KL, Kokko H (2010) Male mate choice: why sequential choice can make its evolution difficult. Anim Behav 80:163-169

Barry KL, Holwell GI, Herberstein ME (2008) Female praying mantids use sexual cannibalism as a foraging strategy to increase fecundity. Behav Ecol 19:710-715

Barry KL, Holwell GI, Herberstein ME (2009) Male mating behaviour reduces the risk of sexual cannibalism in an Australian praying mantid. J Ethol 27:377-383

Barry KL, Holwell GI, Herberstein ME (2010) Multimodal mate assessment by male praying mantids in a sexually cannibalistic mating system. Anim Behav 79:1165-1172

Benjamini Y, Hochberg Y (1995) Controlling the false discovery rate: a practical and powerful approach to multiple testing. J R Stat Soc B (Methodol) 57:289-300

Birkhead TR, Lee KE, Young P (1988) Sexual cannibalism in the praying mantis Hierodula membranacea. Behaviour 106:112-118

Bonduriansky R (2001) The evolution of male mate choice in insects: a synthesis of ideas and evidence. Biol Rev 76:305-339
Brown WD, Muntz GA, Ladowski AJ (2012) Low mate encounter rate increases male risk taking in a sexually cannibalistic praying mantis. PLoS One 7:e35377

Edward DA, Chapman T (2011) The evolution and significance of male mate choice. Trend Ecol Evol 26:647-654

Elgar MA (1992) Sexual Cannibalism in Spiders and Other Invertebrates. In: Elgar MA, Crespi BJ (eds) Cannibalism: ecology and evolution among diverse taxa. Oxford University Press, Oxford, pp $128-155$

Elgar MA, Schneider JM (2004) Evolutionary significance of sexual cannibalism. Adv Stud Behav 34:135-163

Elgar MA, Schneider JM, Herberstein ME (2000) Female control of paternity in the sexually cannibalistic spider Argiope keyserlingi. Proc R Soc Lond B 267:2439-2443

Fromhage L, Schneider JM (2005) Safer sex with feeding females: sexual conflict in a cannibalistic spider. Behav Ecol 16:377-382

Gemeno C, Claramunt J (2006) Sexual approach in the praying mantid Mantis religiosa (L.). J Ins Behav 19:731-740

Holwell GI, Winnick C, Tregenza T, Herberstein ME (2010) Genital shape correlates with sperm transfer success in the praying mantis Ciulfina klassi (Insecta: Mantodea). Behav Ecol Sociobiol 64:617-625

Inoue T, Matsura T (1983) Foraging strategy of a mantid, Paratenodera angustipennis S.: mechanisms of switching tactics between ambush and active search. Oecologia 56:264-271

Jayaweera A, Barry KL (2015) The effect of female quality on male ejaculatory expenditure and reproductive success in a praying mantid. PLoS ONE 10:e0124209

Johns PM, Maxwell MR (1997) Sexual cannibalism: who benefits? Trend Ecol Evol 12:127-128

Lelito JP, Brown WD (2006) Complicity or conflict over sexual cannibalism? Male risk taking in the praying mantis Tenodera aridifolia sinensis. Am Nat 168:263-269

Lelito JP, Brown WD (2008) Mate attraction by females in a sexually cannibalistic praying mantis. Behav Ecol Sociobiol 63:313-320

Liske E, Davis WJ (1987) Courtship and mating behaviour of the Chinese praying mantis, Tenodera aridifolia sinensis. Anim Behav 35:1524-1537

Matsura T, Inoue T (1999) The ecology and foraging strategy of Tenodera angustipennis. In: Prete FR, Wells H, Wells PH, Hurd LE (eds) The praying mantids. The Johns Hopkins University Press, Baltimore, pp 61-68

Maxwell MR (1999) Mating behavior. In: Prete FR, Wells H, Wells PH, Hurd LE (eds) The praying mantids. The Johns Hopkins University Press, Baltimore, pp 69-89

Maxwell MR (2000) Does a single meal affect female reproductive output in the sexually cannibalistic praying mantid Iris oratoria? Ecol Entomol 25:54-62

Maxwell MR, Barry KL, Phillips PM (2010a) Examination of female pheromone use in two praying mantids: Stagmomantis limbata and Tenodera aridifolia sinensis (Mantodea: Mantidae). Ann Entomol Soc Am 100:108-114

Maxwell MR, Gallego KM, Barry KL (2010b) Effects of female feeding regime in a sexually cannibalistic mantid: fecundity, cannibalism, and male response in Stagmomantis limbata (Mantodea). Ecol Entomol 35:775-787

Moya-Laraño J, Pascual J, Wise DH (2004) Approach strategy by which male Mediterranean tarantulas adjust to the cannibalistic behaviour of females. Ethology 110:717-724

Prokop P, Václav R (2008) Seasonal aspects of sexual cannibalism in the praying mantis (Mantis religiosa). $\mathrm{J}$ Ethol 26:213-218

SAS Institute (2009) JMP version 8. SAS Institute Inc., Cary

Scardamaglia RC, Fosacheca S, Pompilio L (2015) Sexual conflict in a sexually cannibalistic praying mantid: males prefer low-risk over high-risk females. Anim Behav 99:9-14 
Schneider JM (2014) Sexual cannibalism as a manifestation of sexual conflict. Cold Spring Harb Perspect Biol 6:a017731
Welke KW, Schneider JM (2012) Sexual cannibalism benefits offspring survival. Anim Behav 83:201-207 